\title{
Making Evidence Based Changes on the Labor Ward of Muhima Hospital: Staff Teaching Staff
}

\author{
Jossette Umucyo ${ }^{1}$, Rondi Anderson ${ }^{1}$ \\ ${ }^{1}$ Mubima Hospital, Kigali, Rwanda
}

\section{Background}

In January 2014 it was noted that Muhima hospital was lagging behind in providing certain aspects of evidenced based care in the labor unit. In particular, there was underuse of delayed cord clamping, skin to skin contact, upright position for labor and delivery, and preparation for newborn resuscitation. On the other hand, there was an overuse of high doses of Pitocin ${ }^{\mathrm{TM}}$ (oxytocin) in the second stage of labor and episiotomy. In addition, there were hygiene issues around patients wearing street clothes in labor and for the delivery, and not having sanitary pads to collect vaginal secretions including blood and amniotic fluid. All these things can lead to increased maternal and neonatal morbidity and mortality.

\section{Description}

A program was put in place that involved staff and midwifery students doing twice weekly presentations on the above topics at morning meetings, with support for their preparation that included learning how to access information from the internet and make a power point presentation. In addition global trainings on helping babies breath, and helping mothers survive were established monthly for all staff. Bedside teaching and mentoring by those in-charge, advanced midwifery students and Human Resources for Health (HRH) faculty of the United States Institute (USI) were involved to translate theory to practice.

At the end of one year we have found that there have been significant changes in clinical practice. Skin to skin with delayed cord clamping after birth is now practiced universally in the labor ward. There is always an AMBU ${ }^{\text {TM }}$ bag (i.e. bag valve mask) present on the warmer. Many woman are using upright positions including squatting for delivery. High doses of oxytocin are no longer seen being given in second stage. Episiotomies are no longer routine and all woman now have adult pampers and hospital gowns.

\section{Lessons Learned}

Staff embraced the change even though initially resistant, learned how to find information on the internet and found that making power points was fun, and evidenced based changes were made.

\section{Conclusion}

Important evidence based changes in clinical care have been made at Muhima hospital by having staff research the internet and teach each other both didactic and clinical content with the support of advanced students and USI HRH faculty.

Key words: cord clamping, skin to skin contact, upright position for labor, oxytocin 